\title{
Debris-flow deposition zones - an example from the southern slopes of Stara Planina Mountain (village of Anton area)
}

\section{Зони на отлагане от кално-каменни потоци - пример от южните склонове на Стара планина (района на с. Антон)}

\section{Zornitsa Dotseva \\ Зорница Доцева}

Sofia University “St. Kliment Ohridski”, 15 Tsar Osvoboditel Blvd, 1504 Sofia, Bulgaria; E-mail: zdoceva@gea.uni-sofia.bg

\begin{abstract}
The analysis of the deposition zones is one of the main steps in the debris flows hazard assessments. For the area located north and northeast of Anton village is known that in the last 100 years there is at least one debris flow event. Field observations, geological characteristics, and raster analysis for prediction of possible sediment accumulations over the fans, related with debris flow activity were performed for preliminary analysis of the debris flows hazard in the area.
\end{abstract}

Keywords: deposition, GIS, debris flows, alluvial fans.

Една от основните стьпки при анализа на опасността от проява на кално-каменни потоци в активните планински райони е изследването на алувиалните конуси и съвременните отложения. Алувиалните конуси се описват като крайна точка на системата ерозия-отлагане, в която седиментите се транспортират и отлагат под формата на речни, смесени или кално-каменни (поройни) конуси според типа на потока, който пренася седиментния материал (Schumm, 1977; Wilford et al., 2004).

Водосборите и алувиалните конуси в южните склонове на Стара планина (Карлово, Казанльк, Златишко) са били обект на изследвания от редица автори (Mishev et al., 1962; Kamenov, Iliev, 1963; Gerdjikov et al., 2012; Kenderova, Baltakova, 2013 и др.). Настоящото изследване е насочено към съвременните отложения, които могат да бъдат наблюдавани върху алувиалните конуси и в речните долини северно от с. Антон (фиг. 1а-в). За района е известно, че е имало поне едно екстремно събитие, свързано с проява на кално-каменни потоци през последните 100 години, което е довело до разрушаването на постройки и инфраструктура (Mishev et al., 1962; Kerenski et al., 1977). Теренни данни от 2016 г. индикират и за съвременно действие на такива потоци, но с много по-мальк интензитет. Освен това, условията във водосборите северно от с. Антон са изключително подходящи за формиране на кално-каменни потоци или потоци от смесен тип при интензивни валежи - голям наклон на склона, достигащ на места над 30-35, присъствие на неспоен материал по склоновете и в речните канали, висока степен на ерозия, геометрични и морфометрични параметри (Dotseva, Gerdjikov, 2020). Като контролиращ фактор трябва да се вземе предвид и активната разседна система в основата на Старопланинския склон, както и реактивирането на по-стари структури в лежащия блок, които са оказали влияние върху еволюцията на дренажната и конусната системи - врязване на речните канали в конусите, намаляване на наклона на склона, оформяне на нови речни легла извън по-старите, формиране на отслабени зони в скалите и т.н. (Mishev et al., 1962; Gerdjikov et al., 2007; Gerdjikov et al., 2012; Glabadanidu et al., 2012).

Освен тези данни, които несъмнено подчертават опасността в района, интересен е и фактьт, че в рамките на няколко километра наблюдаваните съвременни отложения са с различни характеристики и това до голяма степен може да бъде обвързано с вида на седиментите. Литологията на скалите, върху които са формирани водосборите, е фактор за това, какъв поток ще се формира и съответно какви седиментни отложения могат да се очакват, които се разкриват в Старопланинския склон. Литологията е особено важна по отношение на процесите на ерозия и генерирането на материал във водосборите, който може да бъде въвлечен в потока, но също така с нея могат да бъдат свързани специфичните характеристики на отложенията, които са резултат от действието на различните типове потоци 


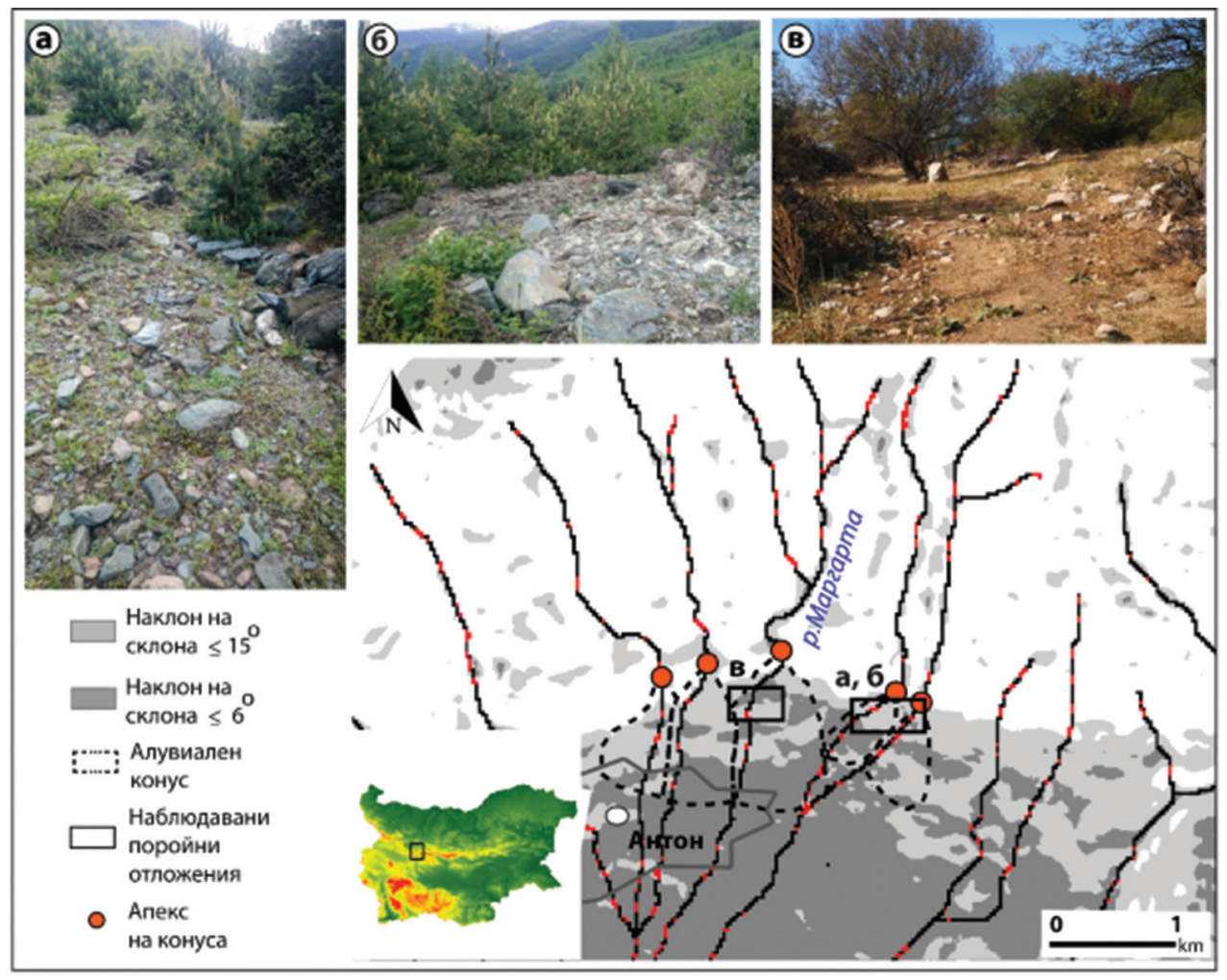

Фиг. 1. Местоположение на изследвания район и зони на отлагане в речните канали (отбелязани в червено), моделирани чрез растерен анализ и коефициент на чувствителност $\mathrm{k}=0,28: a, \sigma$ - слабосортирани отложения, оформящи окрайна дига източно от р. Маргарта (42.73875 N, 24.28970 E); в - несортирани отложения в основата на склона, по повърхността на алувиалния конус западно от р. Маргарта (42.74250 N, 24.27475 E)

(Tiranti et al., 2008, 2014; Tiranti, Deangeli, 2015). За да се определи връзката между литологиите, върху които са формирани водосборите и доминиращия тип на отложенията в алувиалните конуси и речните легла, е използвана CWI класификацията (Clay Weathering Index), която се базира на устойчивостта на дадена литология към изветряне и формиране на глинести минерали (Tiranti et al., 2008). Този подход е успешно прилаган в Западна Европа и на него се базира разработената система за ранно оповестяване DEFENCE (Tiranti et al., 2014). На базата на литологията изследваните водосбори и отложения могат да се привържат към CWI класовете ECM (Excelent Clay Maker) и ВСM (Bad Clay Maker).

Към клас ЕСМ са отнесени двата водосбора и отложенията източно от р. Маргарта там, където водосборите са разположени върху филитизирани и алевритови аргилити (Antonov et al., 2010). Отложенията, свързани с този клас се характеризират със стръмни склонове, асиметрия и градация на скалните късове - от валуни във фронталните части до по-малки класти в „опашката“ на потока. Тези характеристики до голяма степен съвпадат с наблюдаваните източно от p. Маргарта отложения, които са изградени пре- димно от слабосортирани кластични седименти с присъствие на глинеста компонента. Отложенията са във формата на асиметрични валове, покриващи източните брегове на реките, а ориентировката им следва основната посока на потока. Отложенията носят белезите на доминиращи кално-каменни потоци (фиг. 1a, б).

Към клас ВСМ попадат водосбора на р. Маргарта и водосборите западно от нея, чиято площ в по-голямата си част се разполага върху масивни кристалинни скали - гранодиоритите на Веженския плутон (Antonov et al., 2010). Отложенията в тази категория могат да оформят окрайни диги и валове, изградени само от валуни и блокове, без наличие на матрикс. За този клас е характерно присъствието на неактивни склонови отложения в зоните на подхранване и отлагане на късове в речните канали, чиято мобилизация може да се извърши при много екстремни валежи. Такъв тип акумулации са описани на няколко места във водосбора на р. Маргарта (Dotseva, Gerdjikov, 2020). Съвременните отложения се характеризират с концентрация на късове с размер на валуни и спорадично присъствие на скални блокове в апекса на конусите и основата на склона, близо до 
разседната система, изградени главно от метаморфни скали (фиг. 1в). Присъствието на такъв тип отложения отразява интензивната ерозия и акумулация на материал във водосборите, както и вероятно е свързано с действието на смесени потоци (дебритни прииждания).

По отношение на разпространението на съвременните отложения е направен анализ на потенциалните зони на отлагане в речните канали и конусите чрез методиката, предложена от Grelle et al. (2019), която се основава на няколко параметьра - наклон на склона (Slope), крива на наклона (Curvature), и задвижващ фактор (TR). Анализът се извършва в ГИС среда, чрез генерирането на слоеве и използването на растерен калкулатор и бинарни маски. След сензитивен анализ на коефициент $\mathrm{k}$, който най-общо изразява различни условия като валежи, почвен слой и растителност и влияе пряко върху изчисляването на TR индекса, е представен модел на потенциални зони на отлагане при стойност на $\mathrm{k}=0.28$ (фиг. 1). Зоните, които се отделят чрез този анализ, се приемат за зони с потенциална акумулация на материал, който се натрупва след обилни количества на валежи, без да се отчитат характеристики като обем, реология на потока и т.н. Наклонът на склона на конусите, който е един от основните параметри на анализа варира, като малките наклони са резултат от тектонската активност в района, което води до по-фини класти и нисък ьгъл на отлагане за кално-каменните потоци. Според получения модел отлагането на материал се съсредоточава по бреговете на дълбоко врязаните речни канали или на местата, където има промяна в наклона на склона и посоката на потоците. Получените данни от модела съвпадат до голяма степен с реално наблюдаваните зони на отлагане, както в конусите, така и във водосборите.

Един от основните проблеми, които не позволяват пълно характеризиране и разграничаване на съвременните зони на отлагане, е интензивната антропогенна намеса. При прилагането на анализи, свързани с моделиране на разпространението на отложенията, е желателно те да се провеждат възможно най-скоро след дадено събитие или да има наличие на отложения с ясно дефинирани гранци, за да може да се направи правилна съпоставка между резултатите от модела и реалността. Въпреки това, данните, получени от растерния анализ, допълват вече наличната информация за района и са подходящи за предварителна оценка на опасността. Към тях биха могли да се добавят и данни за обема на отложения материал, климатичните и хидроложките особености с цел моделиране на потоците и изготвяне на карти на опасността и риска.
Благодарности: Изследването е финансирано от Национална програма „Млади учени и постдокторанти, 2020“ към Министерство на образованието и науката.

\section{Литература \\ References}

Antonov, M., S. Gerdzhikov, L. Metodiev, Ch. Kiselinov, V. Sirakov, V. Valev. 2010. Geological Map of Bulgaria on Scale 1:50 000. Klisura Map Sheet. Sofia, Geocomplex.

Dotseva, Z., I. Gerdjikov. 2020. Assessment of debris flowsprone watersheds in the southern slopes of Stara planina mountain by combined raster and morphometric analysis. - J. Mining and Geol. Sci., 63, 302-307.

Gerdjikov, I., N. Georgiev, D. Dimov, A. Lazarova. 2007. The different faces of supposedly single thrust: a reevaluation of the Vezhen thrust, Central Balkanides. - In: Proceedings of the National Conference "GEOSCIENCES 2007". Sofia, Bulg. Geol. Soc., 24-26

Gerdjikov, I., D. Vangelov, I. Glabadanidu. 2012. One underestimated geological hazard: the debris flows. - Rev. Bulg. Geol. Soc., 73, 1-3, 85-104 (in Bulgarian with English abstract).

Glabadanidu, I., I. Gerdzhikov, D. Vangelov, 2012. Structural and tectonic geomorphological studies in Zlatitsa graben, Central Bulgaria. - In: Proceedings of the National Conference “GEOSCIENCES 2012”. Sofia, Bulg. Geol. Soc., 107-108.

Grelle, G., A. Rossi, P. Revellino, L. Guerriero, F. M. Guadagno, G. Sappa. 2019. Assessment of debris-flow erosion and deposition areas by morphometric analysis and a GISbased simplified procedure: A case study of Paupisi in the Southern Apennines. - Sustainability, 11, 8, 1-20.

Kamenov, B., I. Iliev. 1963. Engineering geological subdivision of the Republic of Bulgaria. - In: Works on the Geology of Bulgaria, Ser. Engineer. Geology and Hydrogeology, 2, 5-123 (in Bulgarian with Russian and English abstracts).

Kenderova, R., A. Baltakova. 2013. Debris flows in Kazanlak Valley, south slopes of the Balkan Mountain Range, Bulgaria. - J. Geograph. Inst. Jovan Cvijic SASA, 63, 3, 361-370.

Kerenski, S., S. Dimitrov, M. Milchev. 1977. Borba s eroziyata $v$ gorskiya fond na Bulgaria. Sofia, Zemizdat, 161 p. (in Bulgarian)

Mishev, K., V. Popov, Tz. Mihaylov. 1962. Morphologie et néo-tectonique du pied de la Stara-Planina entre les seuils de Galabec et Koznica. - Reviews Inst. Géograph., BAS, 6, 43-61 (in Bulgarian with French abstract).

Schumm, S. A. 1977. The Fluvial System. New York, Wiley, $338 \mathrm{p}$.

Tiranti, D., C. Deangeli. 2015. Modeling of debris flow depositional patterns according to the catchments and source areas characteristics. - Front. Earth Sci., 3, 8, 1-14.

Tiranti, D., S. Bonetto, G. Mandrone. 2008. Quantitative basin characterization to refine debris-flow triggering criteria and processes: an example from the Italian Western Alps. - Landslides, 5, 45-57.

Tiranti, D., R. Cremonini, F. Marco, A. R. Gaeta, S. Barbero. 2014. The DEFENSE (DEbris Flows triggEred by storms - Nowcasting SystEm): an early warning system for torrential processes by radar storm tracking using a Geographic Information System (GIS). - Comput. Geosci., 70, 96-109.

Wilford, D. J., M. E. Sakals, J. L. Innes, R. C. Sidle, W. A. Bergerud. 2004. Recognition of debris flow, debris flood and flood hazard through watershed morphometrics. Landslides, 1, 1, 61-66. 